\title{
Toxicologic evidence of developmental neurotoxicity of environmental chemicals
}

\section{Citation}

Andersen, Helle Raun, Jesper Bo Nielsen, and Philippe Grandjean. 2000. “Toxicologic Evidence of Developmental Neurotoxicity of Environmental Chemicals." Toxicology 144 (1-3) (April): 121127. doi:10.1016/s0300-483x(99)00198-5.

\section{Published Version}

doi:10.1016/S0300-483X(99)00198-5

\section{Permanent link}

http://nrs.harvard.edu/urn-3:HUL.InstRepos:34787289

\section{Terms of Use}

This article was downloaded from Harvard University's DASH repository, and is made available under the terms and conditions applicable to Other Posted Material, as set forth at http:// nrs.harvard.edu/urn-3:HUL.InstRepos:dash.current.terms-of-use\#LAA

\section{Share Your Story}

The Harvard community has made this article openly available.

Please share how this access benefits you. Submit a story.

Accessibility 


\section{Toxicologic evidence of developmental neurotoxicity of environmental chemicals}

Helle Raun Andersen, Jesper Bo Nielsen*, Philippe Grandjean Department of Environmental Medicine, Odense University Winsløwparken 17, DK-5000 Odense C, Denmark

*Corresponding author

Fax: +45 6591 1458; e-mail: jb.nielsen@winsloew.ou.dk 


\begin{abstract}
Developmental neurotoxicity constitutes effects occurring in the offspring primarily as a result of exposure of the mother during pregnancy and lactation. To exert their effect, these chemicals or their metabolites must pass the placenta and/or the blood-brain barrier. In experimental animals, exposure to neurotoxic chemicals during critical periods of brain development has induced permanent functional disturbances in the CNS. Although available data suggest that proper animal models exist, only few chemicals have been tested. Neurotoxicity testing is not required by national authorities for classification of chemicals. Epidemiological evidence is very limited, but severe irreversible effects have been observed in humans following in utero exposures to a few known developmental neurotoxicants. The large number of chemicals with a potential for developmental neurotoxicity in humans stresses the importance of generating basic kinetic data on these chemicals based on relevant experimental models. First of all, data are needed on their ability to pass the placenta and the developing blood-brain barrier, to accumulate, and to be metabolized in the placenta and/or the fetus. These kinetic data will be essential in establishing a scientifically based hazard evaluation and risk assessment.
\end{abstract}

\title{
Keywords:
}

developmental, neurotoxicity, environmental chemicals, transplacental passage 


\section{Introduction}

Developmental neurotoxicity involves alterations in behaviour, neurohistology, neurochemistry, neurophysiology, and/or gross dysmorphology of the central nervous system (CNS) occurring in the offspring as a result of chemical exposure of the mother during pregnancy or during lactation. To reach the fetus, the chemicals must pass the placenta. The use of the term placental barrier often leads to the misconception that the placenta acts as a barrier to protect the fetus against potentially toxic compounds. The placenta should more correctly be perceived as a dynamic and changeable interface that allows transport of essential compounds and nutrients between two compartments. Harmful xenobiotics may, however, also pass this set of membranes. Several neuroactive drugs and substances of abuse (e.g., ethanol, cocaine and heroin) have been documented as human developmental neurotoxicants (Stanton and Spear 1990) while the neurotoxic risk following exposure to environmental chemicals during pregnancy has been investigated only to a limited degree. The purpose of this paper is to describe the extent and significance of present knowledge on adverse effects due to fetal or neonatal exposure to neurotoxic compounds.

\section{Transplacental transfer of neurotoxicants}

Transplacental passage may occur through active transport, facilitated transport or through passive diffusion. The selectiveness of this passage is mainly associated with an active transport of amino acids, glucose, vitamins, and inorganic ions, and the placenta is able to transfer these compounds to the fetus against a concentration gradient, thereby ensuring adequate levels of essential substances for fetal growth (Salama et al. 1993). Some foreign compounds may mimic essential compounds or may be bound to such compounds for which a transport mechanism exists. Thus, some of the toxic metal ions can use existing ion channels 
to pass membranes. Placental permeability to other chemicals is influenced both by placental characteristics (e.g., thickness, area, carrier systems, lipid and protein content) and by chemical characteristics such as the degree of ionization, lipid solubility, protein binding, and molecular weight. Placental blood flow, placental permeability, and placental metabolism which all affect placental transfer of chemicals are not static during pregnancy but change as the gestation progresses (Slikker and Miller 1994).

In adults, neurotoxicants must pass the blood-brain barrier (BBB) to exert their toxic effects. BBB transfer of drugs is correlated to their lipid solubility (Watanabe et al 1990). Therefore, many compounds identified as neurotoxicants in adults have the potential also to pass the placenta rapidly and to reach the fetal circulation upon exposure of the mother. However, to which extent neurotoxic compounds constitute a risk to the fetus is generally not known, partly because of the insufficient knowledge on kinetics of placental passage.

\section{Susceptibility of the developmental nervous system}

Selective susceptibility of the developing nervous system may be due to several toxicokinetic factors, including differences in metabolizing enzymes, rates of excretion, differential binding affinity to target proteins, and partial lack of a BBB in the fetus. The fetal BBB develops during pregnancy and in humans, and the BBB is not fully developed until the middle of the first year of life (Rodier 1995). During this pre- as well as postnatal period with an incomplete BBB, some toxic agents, e.g. cadmium, that are very unlikely to enter the mature brain may pass into the developing brain (Levin and Miller 1980). Further, recent data demonstrate that different classes of pesticides are able to change the permeability characteristics of the BBB in rats when administered during susceptible periods of the BBB development, and this effect 
may persist for varying periods after cessation of exposure (Gupta et al. 1999). A changed BBB may render the nervous system more vulnerable to other toxicants that would otherwise not be able to pass the BBB.

The enhanced susceptibility of the developing brain seems to depend to a great extent on disruption of sensitive processes that occur only during development when the CNS undergoes defined periods of maturation (Tilson 1998), and more data are clearly needed to elucidate the importance of a changed BBB for neonatal neurotoxicity as well as neurological dysfunction of later life.

Although the developing nervous system has some capacity to adapt to or compensate for early perturbations, there is clear evidence that the developing nervous system is more vulnerable to many chemical agents than the adult nervous system (Tilson 1998). During the transition from neuroblasts to mature neurons, cells transiently retain a substantial degree of phenotypic plasticity. A normal microenvironment during these stages is needed to fine-tune the sensory systems which are highly sensitive to microenvironmental manipulation (Kentroti 1997, Ahlbom et al. 1995). The maximum rate of neurogenesis in different parts of the brain occurs during different stages of development (Rodier 1980) but neurogenesis is only one stage of brain ontogeny. Neuron migration, development of receptors and transmitter systems and myelination continue after birth. Besides, it is assumed that neurons once damaged or left behind have a limited capacity for regeneration. Accordingly, exposure to neurotoxic substances during such critical developmental periods can have long-lasting consequences and alter CNS function in a manner that does not compromise the growth and viability of the fetus but causes severe neural and/or behavioural changes. 
In many mammalian species, a rapid growth of the brain occurs, known as the 'brain growth spurt'. In the common laboratory animals (mouse and rat), this period is entirely neonatal, spanning the first 3-4 weeks of life. During this period the brain undergoes several fundamental developmental phases, e.g., maturation of axonal and dendritic outgrowth, establishment of neural connections, synaptogenesis, multiplication of glia cells with accompanying myelination (Dencker and Eriksson 1998). Thus several critical windows for induction of persistent neurotoxic effects may exist during this period of development (Eriksson 1997). In humans, the 'brain growth spurt' begins already during the third trimester of pregnancy and continues throughout the first years of life. Thus, most previous experimental studies on developmental neurotoxicity using in utero exposure may have failed to study this susceptible period. Therefore, species-specific differences in development and maturation of the nervous system need also to be taken into account in relation to risk estimation.

\section{Developmental neurotoxicants in experimental animals}

A large number of chemicals have been reported to be neurotoxic in experimental animals, and many of these compounds have also been found to cause malformations and/or growth abnormalities in the progeny of exposed females, although in some cases only in higher dosages. Several of these compounds could probably also affect the developing nervous system but this aspect has very often not been examined although functional effects have been suggested to be more sensitive (i.e., to occur at lower doses) than teratogenic measurements, such as embryolethality, malformations, and growth retardation (Vorhees 1997).

To identify developmental neurotoxic chemicals, a literature survey (Toxline, OSH-ROM ${ }^{\mathrm{TM}}$ : 
1981-1999) based on key-words ((NEUROTOX* or NEURO near TOX*) and (EMBRYO* or FOETUS* or FETUS* or FOETAL* or FETAL* or POSTNATAL* or NEONATAL* or DEVELOPMENTAL or REPRODUCTION-TOX* or REPRODUCTIVE-TOX* or PLACENTA)) was conducted. After drugs and drugs of abuse were excluded, the compounds demonstrating an adverse effect in the progeny after prenatal exposures in mammals were 21 pesticides, 14 solvents, 9 metals or organometal compounds and 5 other industrial chemicals (Table 1). A similar number of chemicals in the respective categories were identified as developmental neurotoxicants by Goldey et al.(1995) based on a literature search from different sources. This number is certainly not exhaustive and does not provide any evidence of effects in humans. Hence, there is convincing experimental evidence that exposure to low levels of neurotoxic substances during vulnerable developmental periods can induce permanent functional disturbances in CNS. Because the biological processes involved in neurogenesis and maturation of the nervous system are similar in humans and animals, one could expect analogous neurotoxic effects if the compounds can reach the human developing brain in relevant concentrations at critical time points.

\section{Extrapolation from experimental animals to humans}

Several issues must be considered regarding extrapolation between species. The placenta is not static but varies considerably throughout gestation. Humans exhibit two placentae, i.e. the early yolk sac placenta (days 13 to 80 of gestation) which overlaps developmentally with the later chorioallantoic placenta (day 21 to term) (Slikker and Miller 1994). Extrapolation from experimental studies on placental transfer has thus previously been questioned due to differences in membrane structure, i.e., the number of cell layers separating the maternal blood from the fetal blood. Though differences in membrane structure and transit times may 
occur, implications are, however, minimal regarding transplacental passage of essential as well as foreign substances (Salama et al. 1993, Slikker and Miller 1994).

Different in vitro methods have been developed to investigate placental transport of chemicals. The isolated perfused placenta model uses placental tissue from animals or humans (Slikker and Miller 1994). This model can, however, only be used to study chemicals that cross the placenta by passive diffusion (Tuntland et al. 1999) and until now it has mainly been used to study the placental transfer of pharmaceuticals. The in vitro models might though be useful tools to predict the potential for placental transfer of substances occurring in occupational and environmental exposures.

Different pharmacokinetic models have been developed to facilitate extrapolation of placental transfer from animals to humans (Kim et al. 1996). However, a number of factors limit their application in risk assessment, e.g., differences in the binding of the chemicals to serum proteins. Thus, protein binding of individual compounds may change during pregnancy and may vary between mother and fetus. Also, if a chemical has been metabolized to a polar form or conjugated by the fetus, the rate of return to the maternal circulation will be slower than that of the parent compound. Moreover, when considering transport it is important to recognize that the placenta can also be a site for storage of chemicals as well as a site for biotransformation (Slikker and Miller 1994). Hence, chemicals may be detoxified or metabolised to more toxic substances by metabolizing enzymes (e.g., cytochrome P450 enzymes) in the placenta. In the fetus the development of metabolizing enzyme systems varies between species and in humans they are not fully developed during the embryonic/fetal period (Cresteil 1998). 
Species differences in the time of CNS development may impair the use of rodents in these models since some of the targets for neurotoxic chemicals are developed postnatally in rodents but prenatally in other species including humans. Guinea pigs may be a preferable animal model since the time schedule of brain development in this species is more similar to humans. For the few environmental agents known to be developmental neurotoxicants in humans (lead, methylmercury, PCB), developmental toxic effects (e.g. cognitive or motor deficits) have been observed in both humans and laboratory animals. However, for these substances developmental neurotoxicity seems to be induced at lower dose levels in humans than in laboratory animals although quantitative comparisons are hampered by use of different endpoints and insufficient dose-response data (Stanton and Spear 1990, Tilson and Kodavanti 1997).

\section{Environmental human neurotoxicants}

Epidemiological and clinical evidence suggest that developmental neurotoxicity has been underestimated. Based on published information, at least 138 industrial chemicals were rated as neurotoxic to humans, i.e. causing clinical signs and symptoms such as addiction, ataxia, coma, delirium/hallucinations, muscle fasciculations, narcosis, organic psycosyndrome, paralysis, paraesthesia, Parkinsonism, peripheral neuropathy, and tremors (Kimbrough et al. 1989, Grandjean et al. 1991). This group of chemicals included 55 pesticides and related compounds, 24 solvents and other organic compounds, and 18 metals and organometal compounds (Table 2). The remaining neurotoxicants were mainly used in the chemical industry. This number represents human neurotoxicants presently identified. Because valid information on human neurotoxic effects of industrial chemicals is scarce the true number 
may be considerably higher.

For most of the compounds mentioned in Table 2 there is no or only little information about the transplacental risk, and for the few compounds demonstrated to affect the fetus there is continuing controversy about the dose-response relationships. Although most of the neurotoxic chemicals are probably capable of crossing the placenta, convincing evidence on prenatal neurotoxicity in humans is so far restricted to two metals (lead, methylmercury) (Banks et al. 1997, Grandjean et al. 1997) and chlorinated biphenyls (Chen et al. 1992, Tilson and Kodavanti 1997). Thus, insufficient human data poses severe limitations for a scientifically-based risk assessment in relation to developmental neurotoxicity.

\section{Discussion}

Early exposure to lead has dramatically illustrated that developmental exposure to a neurotoxicant may have serious consequences for children in modern society (Banks et al.1997). Much less evidence is available on the effect of other neurotoxicants on the developing nervous system. Only for lead, methylmercury and PCBs is the epidemiological evidence of developmental neurotoxicity convincing (Banks et al. 1997, Grandjean et al. 1997, Chen et al. 1992), although at least 135 other industrial chemicals have caused neurotoxicity in adults, and many additional compounds have been shown to cause such effects in experimental animals. The lack of valid human data may prevent a scientific evaluation of the potential developmental neurotoxic hazard from exposure to these chemicals, thus perhaps leading to insufficient preventive efforts.

Given the substantial difficulties in generating epidemiological data, relevant evidence from 
targeted experimental studies is badly needed. An important task in this respect is a better knowledge on the ability of relevant compounds to pass the human placenta. Especially more information on transfer rates at different stages of pregnancy would be very valuable in order to assess the exposure potential of the fetus at different stages of brain development. More data in this field would also offer opportunity to evaluate to which extent chemicals may be grouped in classes based on their ability to cross the placenta. Structure-penetration studies in this area would be highly relevant.

The vast majority of previous experimental studies on developmental toxicity, including neurotoxicity, has used rodents exposed to a few repeated doses during 6-9 days of the gestational period. Evidence now renders this experimental approach insufficient as severe and irreversible neurotoxic effects may remain undetected. Thus, there is a pertinent need for implementing experimental models able to detect effects occurring throughout gestation and the neonatal period. These models may, depending on the human exposure situation, include continuous exposure or short-term exposure during susceptible pre- or postnatal periods.

\section{Acknowledgement}

This work was supported by the Danish Medical Research Council.

\section{References}

Ahlbom, J., Fredriksson, A., Eriksson, P., 1995. Exposure to an organophosphate (DFP) during a defined period in neonatal life induces permanent changes in brain muscarinic receptors and behaviour in adult mice. Brain Res. 677, 13-19. 
Banks, E.C., Ferretti, L.E., Shucard, D.W., 1997. Effects of low level lead exposure on cognitive function in children: a review of behavioral, neuropsychological and biological evidence. Neurotoxicology 18, 237-281.

Chen, Y.C., Guo, Y.L., Hsu, C.C., Rogan, W.J., 1992. Cognitive development of Yu-Cheng ("oil disease") children prenatally exposed to heat-degraded PCBs. J.A.M.A. 268, $3213-3218$.

Cresteil, T., 1998. Onset of xenobiotic metabolism in children: toxicological implications. Food Addit. Contam. 15 Suppl, 45-51.

Dencker, L., Eriksson, P., 1998. Susceptibility in utero and upon neonatal exposure. Food Addit. Contam. 15 Suppl, 37-43.

Eriksson, P., 1997. Developmental neurotoxicity of environmental agents in the neonate. Neurotoxicology 18, 719-726.

Goldey, E.S., Tilson, H., Crofton, K.M., 1995. Implications of the use of neonatal birth weight, growth, viability, and survival data for predicting developmental neurotoxicity: a survey of the literature. Neurotox. Teratol. 17, 313-332.

Grandjean, P., Sandoe, S.H., Kimbrough, R.D., 1991. Non-specificity of clinical signs and symptoms caused by environmental chemicals. Hum. Exp. Toxicol. 10, 167-173.

Grandjean, P., Weihe, P., White, R.F., Debes, F., Araki, S., Yokoyama, K., Murata, K., Sørensen, N., Dahl, R., Jørgensen, P.J., 1997. Cognitive deficit in 7-year-old children with prenatal exposure to methylmercury. Neurotox. Teratol. 19, 417-428.

Gupta, A., Agarwal, R., Shukla, G.S., 1999. Functional impairment of blood-brain barrier following pesticide exposure during early development in rats. Hum. Exp. Toxicol. $18,174-179$. 
Kentroti, S., 1997. Neuronal plasticity in development: lessons from ethanol neurotoxicity during embryogenesis. Adv. Exp. Med. Biol. 429, 19-37.

Kim, C.S., Binienda, Z., Sandberg, J.A., 1996. Construction of a physiologically based pharmacokinetic model for 2,4- dichlorophenoxyacetic acid dosimetry in the developing rabbit brain. Toxicol. Appl. Pharmacol. 136, 250-259.

Kimbrough, R.D., Mahaffey, K.R., Grandjean, P., Sandoe, S.H., Rustein, D.R., 1989. Clinical effects of environmental chemicals, a guide to etiologic diagnosis. Hemisphere, New York.

Levin, A.A., Miller, R.K., 1980. Fetal toxicity of cadmium in the rat: maternal vs. fetal injections. Teratology 22, 1-5.

Rodier, P.M., 1980. Chronology of neuron development: animal studies and their clinical implications. Dev. Med. Child. Neurol. 22, 525-545.

Rodier, P.M. 1995. Developing brain as a target of toxicity. Environ. Health Perspect. 103 Suppl 6, 73-76.

Salama, A.K., Bakry, N.M., Abou-Donia, M.B., 1993. A review article on placental transfer of pesticides. J. Occup. Med. Toxicol. 2, 383-397.

Slikker, W., Miller, R.K., 1994. Placental metabolism and transfer. Role in developmental toxicology. In: Kimmel, C.A., Buelke-Sam, J. (eds.), Developmental Toxicology, 2nd ed. Raven Press Ltd., New York, pp. 245-283.

Stanton, M.E., Spear, L.P., 1990. Workshop on the qualitative and quantitative comparability of human and animal developmental neurotoxicity, Work Group I report: comparability of measures of developmental neurotoxicity in humans 
and laboratory animals. Neurotoxicol. Teratol. 12, 261-267.

Tilson, H.A., 1998. Developmental neurotoxicology of endocrine disruptors and pesticides: identification of information gaps and research needs. Environ. Health Perspect. 106 Suppl 3, 807-811.

Tilson, H.A., Kodavanti, P.R., 1997. Neurochemical effects of polychlorinated biphenyls: an overview and identification of research needs. Neurotoxicology 18, 727-743.

Tuntland, T., Odinecs, A., Pereira, C.M., Nosbisch, C., Unadkat, J.D., 1999. In vitro models to predict the in vivo mechanism, rate, and extent of placental transfer of dideoxynucleoside drugs against human immunodeficiency virus. Am. J. Obstet. Gynecol. $180,198-206$.

Vorhees, C.V., 1997. Methods for detecting long-term CNS dysfunction after prenatal exposure to neurotoxins. Drug Chem. Toxicol. 20, 387-399.

Watanabe, T., Matsuhashi, K., Takayama, S., 1990. Placental and blood-brain barrier transfer following prenatal and postnatal exposures to neuroactive drugs: relationship with partition coefficient and behavioral teratogenesis. Toxicol. Appl. Pharmacol. 105, $66-77$. 
Table 1. Experimental neurotoxicants reported to cause toxic/adverse effects in offspring after pre- or postnatal exposure.

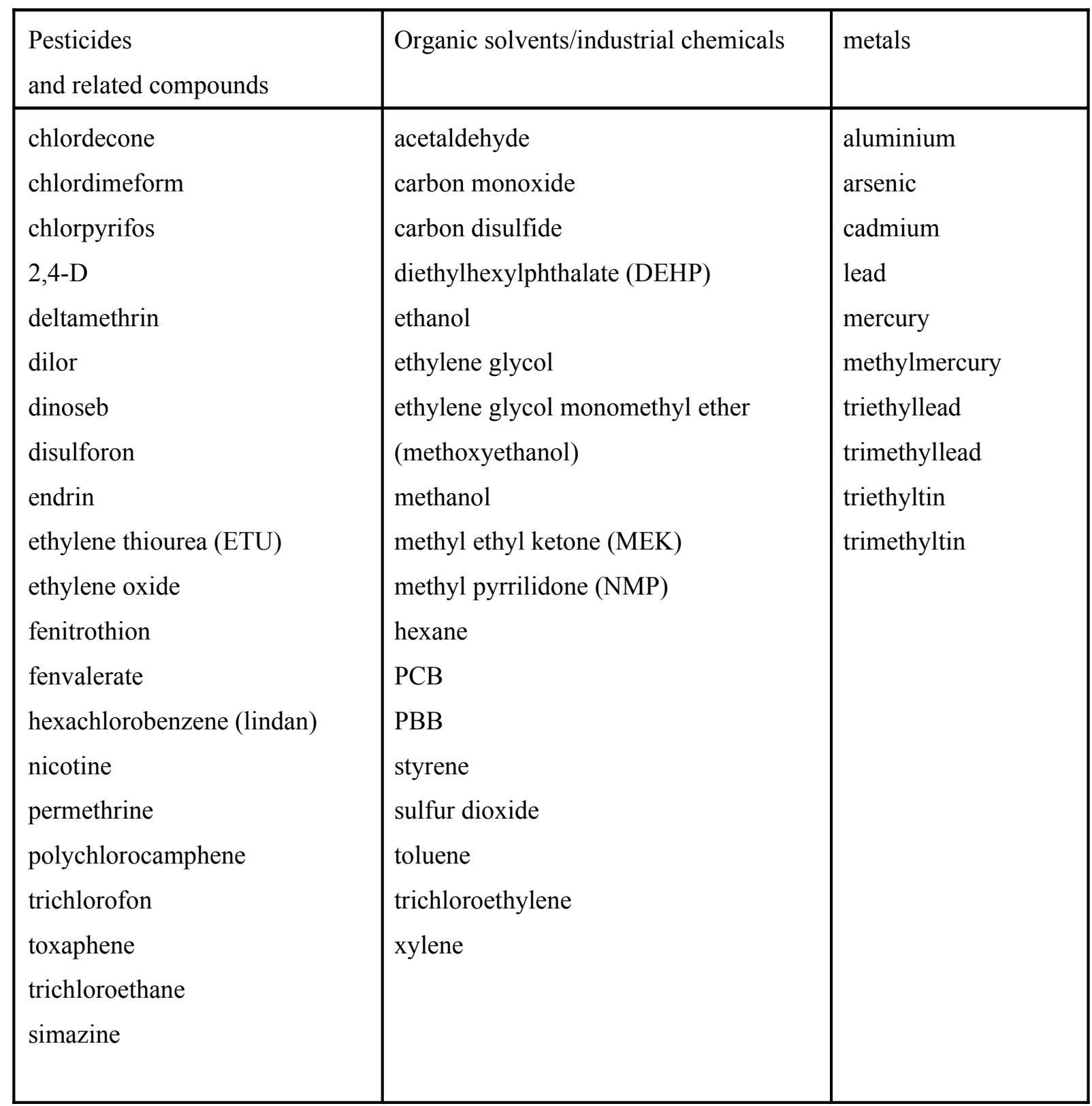


Table 2. Pesticides, solvents and metals rated as neurotoxic in humans.

\begin{tabular}{|c|c|c|c|}
\hline \multicolumn{2}{|c|}{ Pesticides and related compounds } & \multirow{2}{*}{$\begin{array}{c}\begin{array}{c}\text { Solvents and other } \\
\text { organic compounds }\end{array} \\
\text { Acetone cyanohydrin }\end{array}$} & \multirow{2}{*}{$\begin{array}{c}\begin{array}{c}\text { Metal and metal } \\
\text { compounds }\end{array} \\
\text { Aluminum }\end{array}$} \\
\hline Aldrin & Formothion & & \\
\hline Carbophenothion & Isopestox (Mipafox) & Allyl chloride & Arsenic \\
\hline Chlordane & Isopropylphenylmethylcarbama & Benzene & Arsine \\
\hline Chlorfenvinphos & $\mathrm{t}$ & Carbon disulfide & Barium \\
\hline Chlorpyrifos & Kepone (Chlordecone) & a-Chloralose & Bismuth \\
\hline (Dursban) & Leptophos & Chloroform & Lead \\
\hline Chlorthion & Lindane $(, y-H C H)$ & Ethanol & Manganese \\
\hline Cyanides & Malathion & Ethylene glycol & Mercury \\
\hline $2,4-\mathrm{D}$ & Merphos & Ethylene oxide & Methylmercury \\
\hline DDT & Metaldehyde & n-Hexane & Nickel carbonyl \\
\hline DNOC & Methamidophos & Isopropyl alcohol & Selenium \\
\hline Demeton (Systox) & Methidathion & Methanol & Selenium oxide \\
\hline Dialifos & Methomyl & Methyl n-butyl ketone & Tellurium \\
\hline Diazinon & Methyl demeton & Methyl cellosolve & Tetraethyllead \\
\hline Dichlofenthion & Methyl parathion & Methyl chloride & Thallium \\
\hline Dichlorvos & Mevinphos (Phosdrin) & Methylene chloride & Triethyltin \\
\hline Dieldrin & Mexacarbate & 2-Nitropropane & Trimethyltin \\
\hline Dimefox & Monocrotophos & Perchloroethylene & Triphenyltin \\
\hline Dimethoate & Oxydemeton-methyl & Phenol & \\
\hline Dinoseb & Parathion & Tetrachloroethane & \\
\hline Dioxathion & Phorate & Toluene & \\
\hline EPN & Phosphamidon & 1,1,1-Trichloroethane & \\
\hline Endosulfan & Schradan & Trichloroethylene & \\
\hline Endothion & Sodium cyanate & Trimethylene trinitramine & \\
\hline Endrin & Thiram & $(\mathrm{RDX})$ & \\
\hline Fenitrothion & Toxaphene (Camphechlor) & & \\
\hline Fensulfothion & Trichlorfon & & \\
\hline Fenthion & Tri-o-cresylphosphate & & \\
\hline Fonofos & & & \\
\hline
\end{tabular}

